\title{
Linked Patient-Reported Outcomes Data From Patients With Multiple Sclerosis Recruited on an Open Internet Platform to Health Care Claims Databases Identifies a Representative Population for Real-Life Data Analysis in Multiple Sclerosis
}

Valery Risson ${ }^{1}$, MBA, PhD; Bhaskar Ghodge ${ }^{2}$, MCA; Ian C Bonzani ${ }^{3}$, PhD; Jonathan R Korn ${ }^{4}$, BA; Jennie Medin ${ }^{1}$, MPH, PhD; Tanmay Saraykar ${ }^{5}$, MBA; Souvik Sengupta ${ }^{2}$, BE; Deepanshu Saini ${ }^{6}$, MBA; Melvin Olson ${ }^{1}$, PhD

\footnotetext{
${ }^{1}$ Novartis Pharma AG, Basel, Switzerland

${ }^{2}$ IMS Health, Basel, Switzerland

${ }^{3}$ IMS Health, London, United Kingdom

${ }^{4}$ IMS Health, Burlington, MA, United States

${ }^{5}$ IMS Health, Parsippany, NJ, United States

${ }^{6}$ IMS Health, Gurgaon, Delhi, India
}

Corresponding Author:

Valery Risson, MBA, PhD

Novartis Pharma AG

Postfach

Basel, 4002

Switzerland

Phone: 41613246036

Fax: 41613248001

Email: valery.risson@ novartis.com

\begin{abstract}
Background: An enormous amount of information relevant to public health is being generated directly by online communities. Objective: To explore the feasibility of creating a dataset that links patient-reported outcomes data, from a Web-based survey of US patients with multiple sclerosis (MS) recruited on open Internet platforms, to health care utilization information from health care claims databases. The dataset was generated by linkage analysis to a broader MS population in the United States using both pharmacy and medical claims data sources.
\end{abstract}

Methods: US Facebook users with an interest in MS were alerted to a patient-reported survey by targeted advertisements. Eligibility criteria were diagnosis of MS by a specialist (primary progressive, relapsing-remitting, or secondary progressive), $\geq 12$-month history of disease, age 18-65 years, and commercial health insurance. Participants completed a questionnaire including data on demographic and disease characteristics, current and earlier therapies, relapses, disability, health-related quality of life, and employment status and productivity. A unique anonymous profile was generated for each survey respondent. Each anonymous profile was linked to a number of medical and pharmacy claims datasets in the United States. Linkage rates were assessed and survey respondents' representativeness was evaluated based on differences in the distribution of characteristics between the linked survey population and the general MS population in the claims databases.

Results: The advertisement was placed on 1,063,973 Facebook users' pages generating 68,674 clicks, 3719 survey attempts, and 651 successfully completed surveys, of which 440 could be linked to any of the claims databases for 2014 or 2015 (67.6\% linkage rate). Overall, no significant differences were found between patients who were linked and not linked for educational status, ethnicity, current or prior disease-modifying therapy (DMT) treatment, or presence of a relapse in the last 12 months. The frequencies of the most common MS symptoms did not differ significantly between linked patients and the general MS population in the databases. Linked patients were slightly younger and less likely to be men than those who were not linkable.

Conclusions: Linking patient-reported outcomes data, from a Web-based survey of US patients with MS recruited on open Internet platforms, to health care utilization information from claims databases may enable rapid generation of a large population of representative patients with MS suitable for outcomes analysis. 
(J Med Internet Res 2016;18(9):e249) doi: 10.2196/jmir.5805

\section{KEYWORDS}

Internet; multiple sclerosis; outcomes assessment; linkage analysis

\section{Introduction}

The Internet and social media are driving a revolution in communication and information sharing, with a fundamental impact on health care. Patients' voices have become more influential through the exchange of information in the form of conversations, blogs, tweets, and other postings on social media. This development is changing the power balance in decisions regarding health care, requiring traditional stakeholders to recognize patients' perspectives in the provision and evaluation of treatments [1-3].

An enormous amount of information relevant to public health is being generated directly by online communities [4,5]. Epidemiology [6,7], pharmacovigilance [8,9], identification of malpractice [10], and the support of health behavior changes [11] are only a few examples of areas where informal data have been successfully applied. Moreover, the Internet and particularly social networks represent a large number of individuals with shared interests, nationalities, or characteristics that can be reached by relatively modest financial or human resources.

We have previously reported on the feasibility of applying social media listening (defined as the mining and analysis of information gathered from social media) to retrospective analyses in outcomes research, specifically the use of patient-reported reasons for switching between different treatment modalities for multiple sclerosis (MS) [12]. The ability to include patient-reported information to enhance prospective analyses of sources such as claims databases would appear to have great promise in outcomes research. We present here an approach to create a dataset that contains both patient outcomes data (from a Web-based survey of US patients with MS recruited on an open Internet platform) and health care utilization information from claims databases. A linkage analysis has recently been performed on data from dedicated patient platforms and invited patients [13]. We hypothesized that linking patient data from the social media survey with those from the claims databases could identify a representative population that can be used for real-life data analysis in MS. The initial analysis focused on verifying the method by demonstrating that the characteristics of the linked population recruited on the open Internet platform are representative of the MS population in the United States.

\section{Methods}

\section{Study Aim and Design}

The primary aim of this pilot study was to explore the feasibility of creating a dataset that links patient-reported outcomes data, from a Web-based survey of US patients with MS recruited on open Internet platforms, to health care utilization information from health care claims databases. The representativeness of the linked populations was validated by a comparison with the characteristics of known MS populations in the United States.

This study was designed, implemented, and reported in accordance with the Guidelines for Good Pharmacoepidemiology Practices of the International Society for Pharmacoepidemiology [14], the Strengthening the Reporting of Observational Studies in Epidemiology (STROBE) guidelines [15], and the ethical principles laid down in the Declaration of Helsinki [16]. The secondary data source used for the analysis meets all of the US Health Insurance Portability and Accountability Act (HIPAA) compliance standards, ensuring patient anonymity. As such, approval from an institutional review board was not necessary.

The defined target population was a broad, US-based, commercially insured population with MS diagnosed and treated by a specialist. All participants took part in the survey entirely of their own volition, and complete information regarding how the data would be used was provided before patients agreed to take part. Full anonymity was guaranteed at all points of the process of running the survey and performing the linkage and subsequent analysis.

\section{Recruitment and Survey}

The survey process is shown schematically in Figure 1. US Facebook users with an interest in MS were alerted to a patient-reported survey by targeted advertisements. The identification of users with a high interest in MS for the placement of advertisements was performed by Facebook as a commercial service and was beyond the control of the researchers. Users clicking on the survey advertisement were provided a disclaimer on the study and how data would be used, followed by options to decline or consent to proceed to the survey. Users were anonymous until the time at which they consented to taking the survey and passed the screening criteria. No identifiable information was collected from users who declined to take the survey. Users who agreed to participate were redirected away from the Facebook domain to the survey, which was hosted on a secure third-party site accessed using an https (hypertext transfer protocol, secure) protocol. Neither the advertisements nor the survey was branded by any commercial entity.

Before completing the survey, patients were screened for eligibility. Screening questions are presented in Textbox 1 . The predefined criteria were a diagnosis of MS by a specialist; $\geq 12$ months of history of diagnosed disease before taking the survey; 18-65 years of age; and commercial health insurance, both current and in the $\geq 12$ months before study entry. The disease could be primary progressive, relapsing-remitting, or secondary progressive MS. 
Textbox 1. Screening questions.

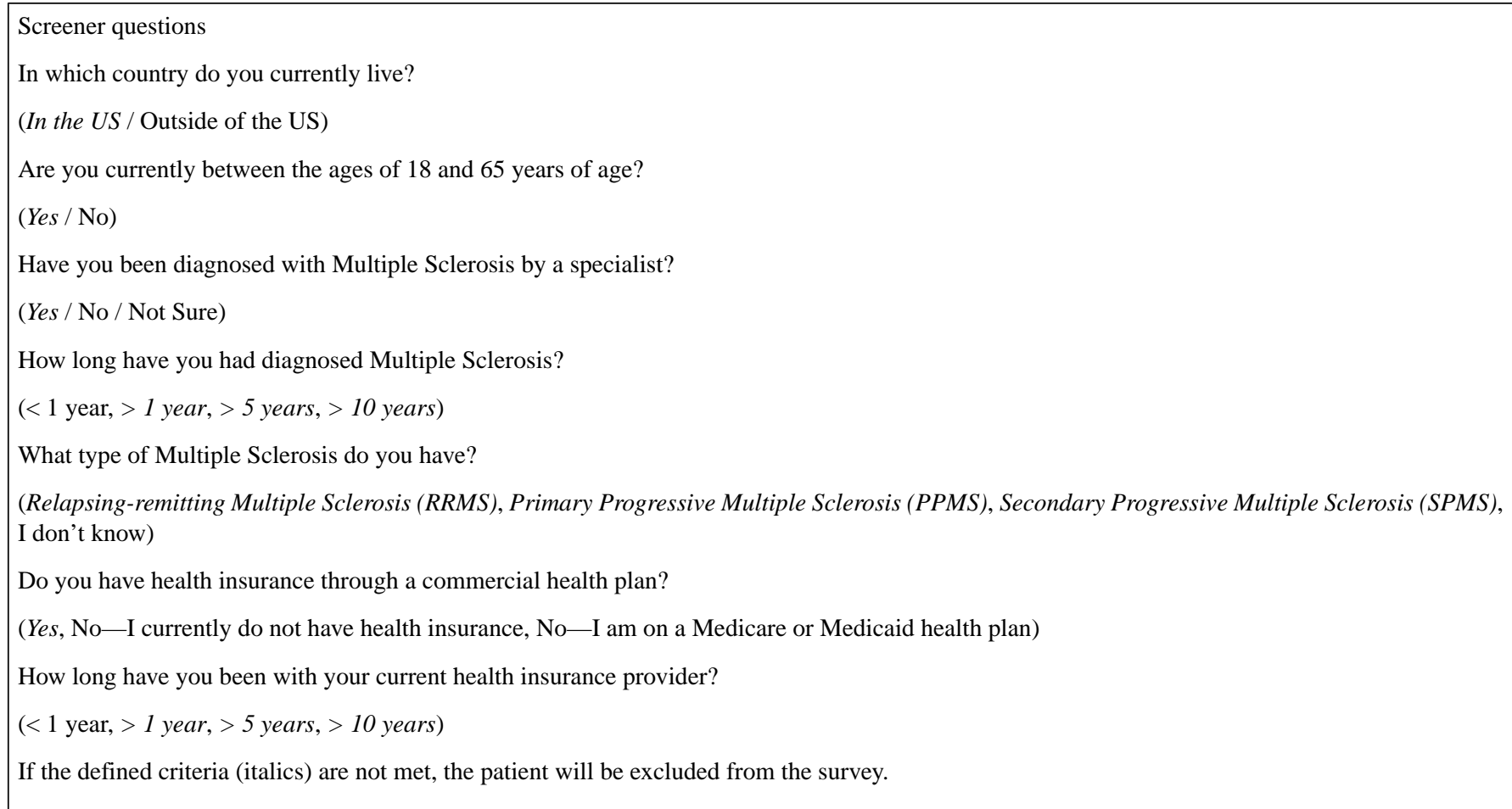

The survey was designed to provide information on demographics and disease characteristics, current and earlier therapy use, relapses, disease severity and disability, health-related quality of life (on the EQ-5D-3L and EQ-VAS scales), and employment status and productivity. The survey is included in Multimedia Appendix 1. Survey participants were informed about data handling, anonymity, and the right to revoke consent in a disclaimer, provided in Multimedia Appendix 2.

All data were hosted in a secure data enclave using network firewalls. Access was provided only to named users who had successfully completed training on the handling of health information and signed data nondisclosure agreements. Before the linkage testing, all data collected from the Web-based survey were deidentified by a trusted third party (Management Science Associates Inc, Pittsburgh, PA), using patient deidentification software, encrypting patients' protected health information data elements in accordance with the Expert Determination De-Identification methodology of the HIPAA Privacy Rule law. The linkage to claims data and subsequent analyses were performed on the deidentified survey population.

Figure 1. Survey and linkage analysis process. MS: multiple sclerosis.

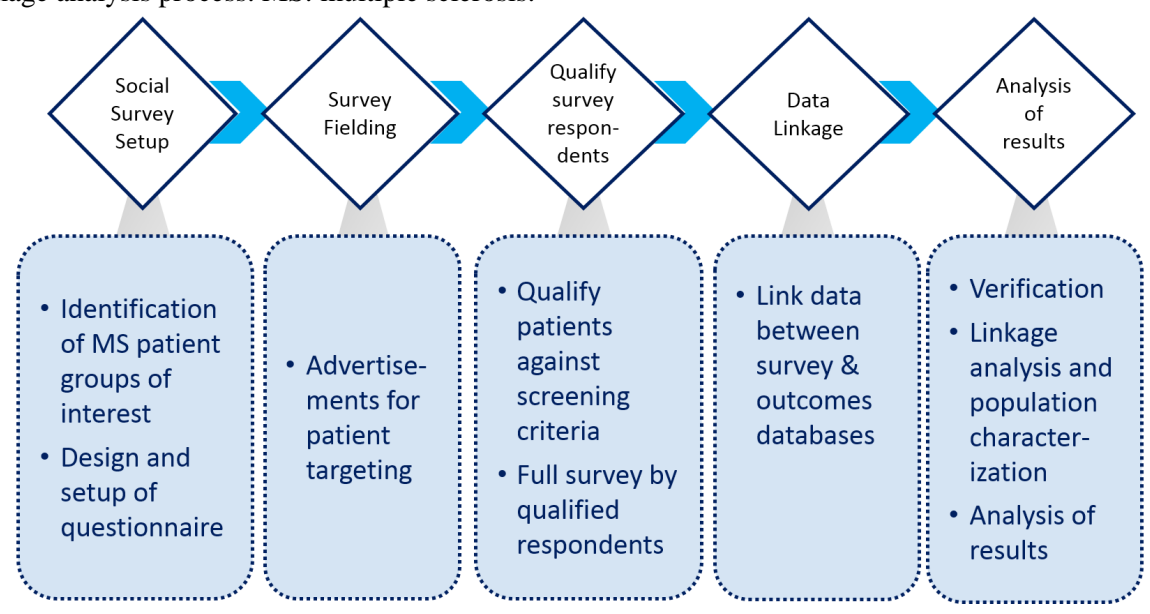

\section{Linkage Analysis}

We included 3 claims databases in the linkage analysis: the preadjudicated provider- and pharmacy-level (open-source) medical claims (Dx) and prescription claims (Rx) databases and the commercial health plan PharMetrics Plus database of adjudicated medical and pharmacy claims. The databases are characterized in Multimedia Appendix 3. The Dx and Rx databases were merged for the linkage analysis (forming the $\mathrm{Dx} / \mathrm{Rx}$ database). The quality of the records in the adjudicated, plan-level PharMetrics Plus database is overall higher than the open-source Rx pharmacy and Dx medical claims databases. The latter has the advantage of covering a larger number of patients. An overview of the different types of information captured in the survey and in the individual databases is shown in Figure 2. 
To link a completed survey to an entry in any of the claims databases, survey respondents' data (eg, name, address, zip code, date of birth, sex) were deidentified by means of a multilevel encryption process that was combined with administrative, physical, and technical safeguards to generate unique, encrypted, deidentified tokens that could not be reidentified. The tokens were used in a deterministic matching process to similarly anonymized patients with claims in the IMS
Health database. A detailed review of the anonymization and linking methodologies is beyond the scope of this paper, but the methodologies have been used extensively, including in the study cited above [13]. For details, the reader is referred to earlier publications available on the Web [17]. Successful linkage was defined as a match in the claims database to the same anonymous profile in a deterministic process.

Figure 2. Overview of the data available in the different sources included in the linkage analysis. The cohorts identified in the medical claims (Dx) and prescription claims $(\mathrm{Rx})$ databases were merged for the linkage analysis. *Via International Classification of Diseases, Ninth Revision, codes. **All claims may not have been captured owing to the possibility of patients using providers or pharmacies not in the database. PMTX+: PharMetrics Plus; QoL: quality of life.

\begin{tabular}{|c|c|c|c|c|c|c|c|}
\hline Data of interest & $\begin{array}{l}\text { Social } \\
\text { Survey }\end{array}$ & $\begin{array}{l}\text { PMTX+ Claims } \\
\text { (closed- } \\
\text { source) }\end{array}$ & $\begin{array}{l}\text { Medical } \\
\text { Claims (Dx) } \\
\text { (open source) }\end{array}$ & $\begin{array}{l}\text { Pharmacy } \\
\text { Claims (Rx) } \\
\text { (open source) }\end{array}$ & Analysis: & & \\
\hline Demographics & $\checkmark$ & $\checkmark$ & $\checkmark$ & $\checkmark$ & & \multirow{13}{*}{$\begin{array}{l}2 \\
\text { Generalizability }\end{array}$} & \\
\hline Geography & $\checkmark$ & $\checkmark$ & $\checkmark$ & $\checkmark$ & & & \\
\hline Diagnosis & $\checkmark$ & $\checkmark$ & $\checkmark^{* *}$ & $\checkmark^{* *}$ & Validation & & \\
\hline Medication use & $\checkmark$ & $\checkmark$ & $\sqrt{ }^{* *}$ & $\checkmark$ & & & \\
\hline Symptoms * & & $\checkmark$ & $\sqrt{ }^{* *}$ & & & & \\
\hline Comorbidities * & & $\checkmark$ & $\checkmark^{* *}$ & & & & \\
\hline $\begin{array}{l}\text { Outpatient visits } \\
\text { \& procedures }\end{array}$ & & $\checkmark$ & $\checkmark$ & & & & $\begin{array}{l}\text { Analysis } \\
\text { of Results }\end{array}$ \\
\hline $\begin{array}{l}\text { In-patient visits \& } \\
\text { procedures }\end{array}$ & & $\checkmark$ & $\checkmark^{* \star}$ & & & & \\
\hline Costs & & $\checkmark$ & & & & & \\
\hline $\begin{array}{l}\text { Disease } \\
\text { characteristics }\end{array}$ & $\checkmark$ & & & & & & \\
\hline Disease Severity & $\checkmark$ & & & & & & \\
\hline QoL & $\checkmark$ & & & & & & \\
\hline Work Productivity & $\checkmark$ & & & & & & \\
\hline
\end{tabular}

\section{Validation}

A total of 4 cohorts were generated for the linkage analysis: cohort 1 , all survey participants; cohort 2 , survey population successfully linked to the PharMetrics Plus or Dx/Rx claims; cohort 3, survey patients not linkable to claims sources; and cohort 4, patients with MS in PharMetrics Plus. Cohort 4 was made up of all patients with MS in the PharMetrics Plus database aged 18-65 years with $\geq 1$ MS diagnosis and $\geq 1$ month of health plan enrollment between January 1, 2013, and March 31, 2015. For further characterization of linked populations, a subset of linked patients was selected with claims from 2014 or 2015. This was in order to take into account availability of newer therapies and to reduce the discrepancy between the dates of the survey and those of historical claims.

An index date of March 31, 2015 was assigned for all survey patients. For the overall MS population in PharMetrics Plus, the index date was the last month of enrollment between January 1, 2013 and March 31, 2015. For all patients, demographic and clinical characteristics were analyzed and compared for 12 months before the index date.

To validate the representativeness of the cohort identified in the linkage analysis, the degree of concordance between the characteristics of the survey population and those identified in the claims databases was analyzed. Concordance was estimated by calculating the positive predictive values (PPVs; the probability that a claimed characteristic in the survey corresponded to the presence of same characteristic in the linked data). Positive predictive values were calculated as follows: $a /(a+b) \times 100$, where $a=$ the number of survey respondents with a specific claim also found in the linked database and $b=$ the total number of survey respondents with the claim. Positive predictive values were calculated for the variables MS diagnosis, current use of disease-modifying therapies (DMTs), prior DMT use, and relapses.

Furthermore, the means and distribution profiles of disease characteristics of all included cohorts were analyzed and compared between the cohorts as follows: cohorts 1 and 4 were compared on demographic characteristics. Cohorts 2 and 4 were compared on clinical characteristics before the index date: use of DMTs, dalfampridine, and corticosteroids (all databases), and comorbidity profiles and Charlson score, use of magnetic resonance imaging of the brain and spine, and relapse rates (PharMetrics Plus only). Cohorts 2 and 3 were compared on all survey results.

\section{Sample Size}

Data on around 302,000 patients with MS were available from the open-source Dx/Rx MS database. The PharMetrics Plus MS database includes data on $>100,000$ patients in a given year. On the basis of preliminary data and pilot study experience, a $10 \%-15 \%$ linkage rate was expected between the survey and PharMetrics Plus MS cohorts and a linkage rate of $>50 \%$ to the $\mathrm{Dx} / \mathrm{Rx}$ cohort. On the basis of these assumptions, a survey sample size of 1000 participants was targeted. 


\section{Statistical Methods}

Demographic data were analyzed descriptively. Categorical variables are presented as frequency and percentage (\%) of total patients observed in each category. Continuous variables are presented as mean (SD) as well as the median. Statistical significance testing used the chi-square test for categorical variables and the Wilcoxon rank sum test for continuous variables. A $P$ value of $<.05$ was considered statistically significant.

\section{Results}

\section{Facebook Survey Participants}

The flow of respondents to the Web-based advertisements and the survey is shown in Figure 3. The Web-based survey was run between July 21, 2015 and September 15, 2015. During this time, the advertisement was placed on 1,063,973 Facebook users' pages. The advertisements generated a total of 68,674 clicks leading to 3719 attempts at the survey. After filtering out respondents who did not meet the criteria for the survey, 685 respondents completed the survey successfully. The characteristics of 34 respondents were indicative of duplications; thus, 651 unique surveys were included in the linkage analysis (651/1040; 62.60\% response rate among eligible respondents who passed screening). 
Figure 3. Flow of respondents.

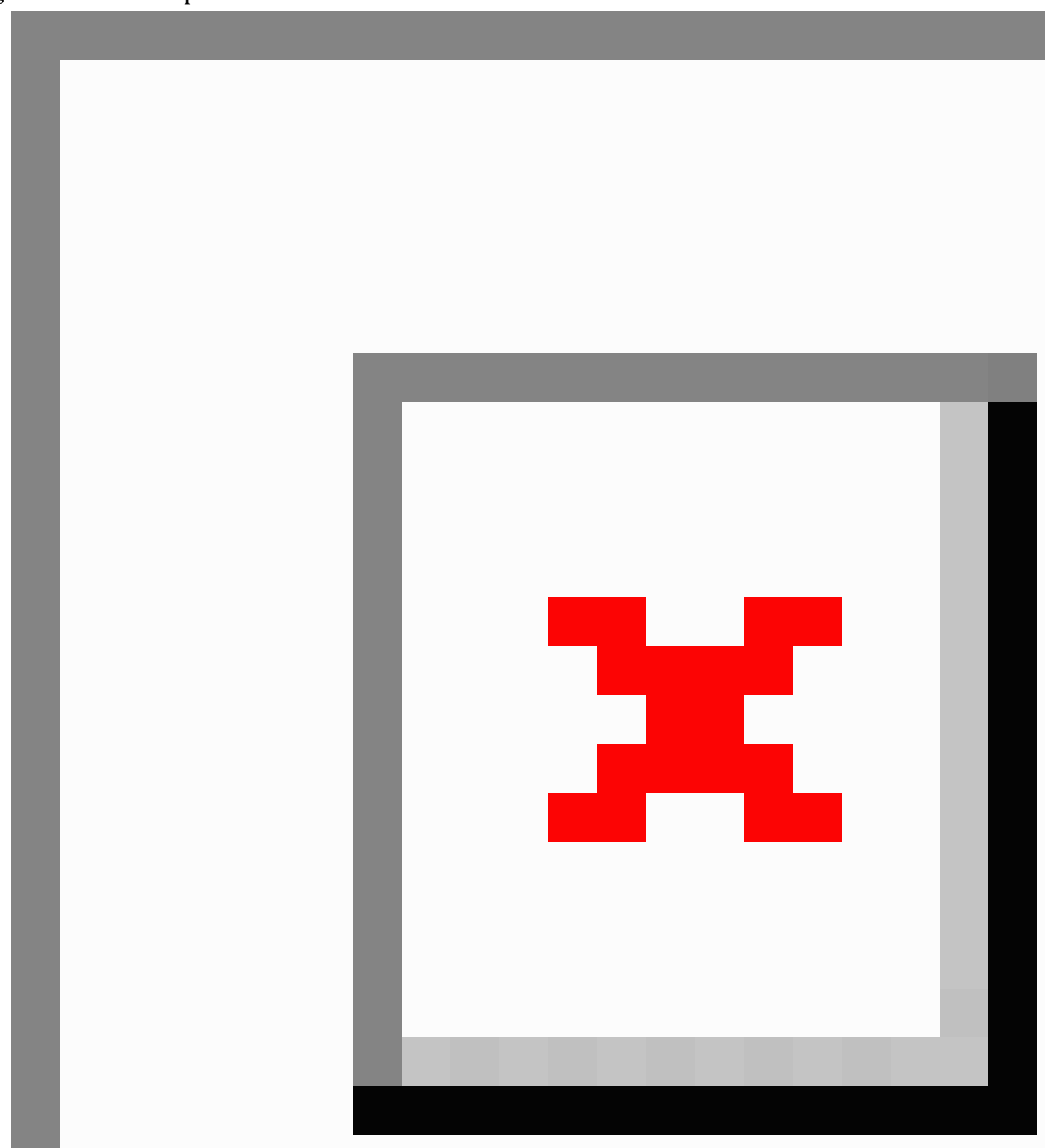

\section{Data Linkage and Validation}

Of the 651 unique patients completing the survey, 453 (69.6\%) could be linked with the Dx/Rx database and 73 (11.2\%) were linkable to the PharMetrics Plus MS database. A total of 198 survey participants could not be linked; a major reason for this was incorrectly entered data, mostly dates of birth that were missing or incorrect for 67 respondents.

The subset of linked patients with claims from 2014 or 2015 used in further characterization consisted of 440/651 patients (67.6\%), 387 of whom $(88.0 \%)$ were linked to the $\mathrm{Dx} / \mathrm{Rx}$ database only and $53(12.0 \%)$ to the PharMetrics Plus MS database.

There was a high degree of concordance between the linked patients and the PharMetrics Plus database (Table 1), whereas concordance with Dx/Rx plus PharMetrics Plus was moderate. The PPV for MS diagnosis in the linked patients was $98.1 \%$ with PharMetrics Plus (88.0\% for all 3 databases), that for current DMT use was $86.5 \%$ (51.7\%), and that for prior DMT use was $70.0 \%$ (47.7\%). The PPV for relapses, 34.6\%, was lower than that for the other variables. 
Table 1. Concordance between data from the Web-based survey and the PharMetrics Plus and Dx/Rx + PharMetrics Plus databases.

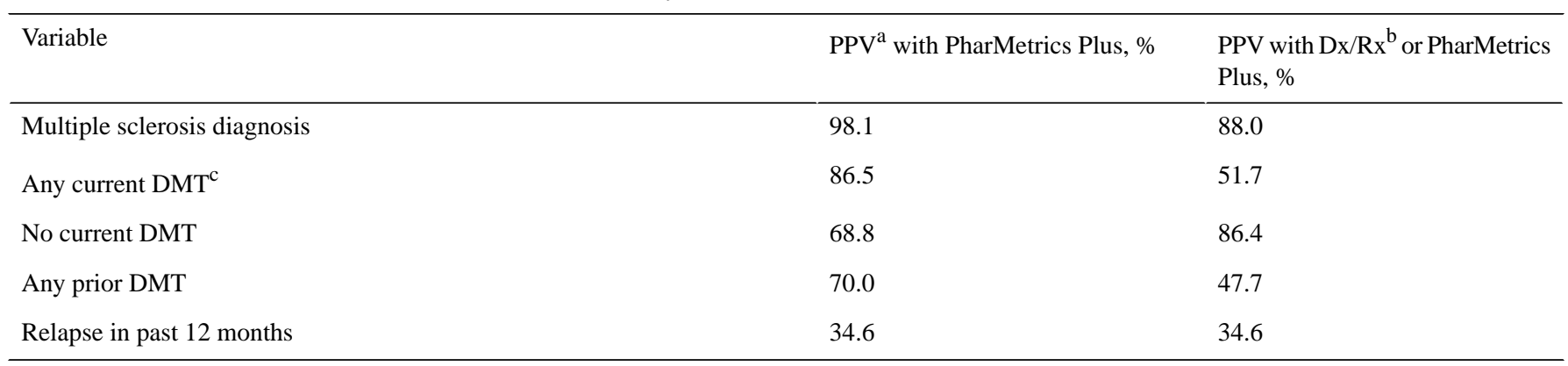

${ }^{\mathrm{a}} \mathrm{PPV}$ : positive predictive value.

${ }^{\mathrm{b}} \mathrm{Dx} / \mathrm{Rx}$ : merged medical claims (Dx) and prescription claims (Rx) databases.

${ }^{\mathrm{c}} \mathrm{DMT}$ : disease-modifying therapy.

\section{Generalizability of Survey Data}

A comparison of those linkable to the PharMetrics Plus or the $\mathrm{Rx} / \mathrm{Dx}$ databases in 2014 or 2015 and those not linkable can be found in Table 2. Overall, patients linkable to the open-source databases had slightly greater mean and median age and were more likely to be men than those linkable to PharMetrics Plus. Patients not linkable to the PharMetrics Plus database were more evenly distributed geographically across the United States, a consequence of underrepresentation of this database in the western states (IMS Health internal data). No significant differences were found for educational status, ethnicity, current or prior DMT treatment, or presence of a relapse in the last 12 months between linkable and not linkable individuals.

Because of the complete coverage of health care claims (eg, low likelihood of missing claims compared with open-source databases) captured in the PharMetrics Plus, the additional analysis presented below focuses on the survey patients linked to the PharMetrics Plus MS database.

Among the most common MS symptoms, the frequencies of a majority of symptoms did not differ significantly between the linked patients and the general PharMetrics Plus MS population
(Figure 4). The rate of gait, balance, and coordination problems was higher in the linked population (16/53 or $30 \%$ vs $14,500 / 82,845$ or $17.50 \%$; $P=.015)$ as was rate of bladder dysfunction ( $12 / 53$ or $23 \%$ vs $9421 / 82,845$ or $11.37 \%$; $P=.0098)$. The rate of numbness was lower in the linked population, but this result was not statistically significant $(5 / 53$ or $9 \%$ vs $16,452 / 82,845$ or $19.86 \% ; P=.057)$. Among comorbidities, only rates of depression differed significantly between the groups, with 21/53 (40\%) linked patients reporting depression compared with $22.21 \%(18,402 / 82,845)$ of the overall PharMetrics Plus MS population $(P=.0023)$. The proportion of patients with relapses based on a claims-based algorithm in the linked cohort was comparable to that in the overall PharMetrics Plus MS cohort: $11 / 53(21 \%)$ in the linked cohort versus $15,723 / 82,845$ $(18.98 \%)$ in the claims database $(P=.7417)$.

Medication use was analyzed for the different populations, displayed graphically in Figure 5. The use of DMTs and corticosteroids was highly similar in the linked cohorts and the overall PharMetrics Plus MS population, whereas more patients in the linked cohort than in the overall population reported dalfampridine use. However, dalfampridine was low in all study populations. 
Table 2. Demographic and clinical characteristics of the population included in the linkage analysis and the general multiple sclerosis population in the PharMetrics Plus and the Dx/Rx databases, respectively.

\begin{tabular}{|c|c|c|c|c|c|}
\hline Characteristic & $\begin{array}{l}\text { Not linkable to PharMet- } \\
\text { rics Plus or } \mathrm{Dx} / \mathrm{Rx}^{\mathrm{a}} \\
(\mathrm{N}=211)\end{array}$ & $\begin{array}{l}\text { Linkable to PharMet- } \\
\text { rics Plus } \\
(\mathrm{N}=53)\end{array}$ & $P$ value & $\begin{array}{l}\text { Linkable to } \\
\text { Dx/Rx } \\
(\mathrm{N}=387)\end{array}$ & $P$ value \\
\hline Age in years, mean (SD) & $46.0(14.7)$ & $48.9(8.6)$ & & $51.2(8.8)$ & \\
\hline Median age, years & 50 & 49 & .79 & 52.0 & .004 \\
\hline Female sex, n (\%) & $178(84.4)$ & $46(87)$ & .66 & $318(82.2)$ & .50 \\
\hline \multicolumn{6}{|l|}{ Region, n (\%) } \\
\hline Northeast & $37(17.5)$ & $18(34)$ & & 75 (19.4) & \\
\hline Midwest & $51(24.2)$ & $16(30)$ & & $114(29.5)$ & \\
\hline South & $64(30.3)$ & $17(32)$ & & $128(33.1)$ & \\
\hline West & $59(28.0)$ & $2(4)$ & $<.001$ & $70(18.1)$ & .0435 \\
\hline Ethnicity: white, n (\%) & $186(88.2)$ & $50(94)$ & & $361(93.3)$ & \\
\hline \multicolumn{6}{|l|}{ Educational status, n (\%) } \\
\hline Less than high school & $5(2.4)$ & $1(2)$ & .92 & $7(1.8)$ & .25 \\
\hline Completed high school & $43(20.4)$ & $11(21)$ & & $71(18.1)$ & \\
\hline Some college & $78(37.0)$ & $17(32)$ & & $141(36.4)$ & \\
\hline Completed college & $65(30.8)$ & $17(32)$ & & $106(27.4)$ & \\
\hline Graduate school & $20(9.5)$ & $7(13)$ & & $62(16.0)$ & \\
\hline \multicolumn{6}{|l|}{ MS $^{\mathbf{b}}$ subtype, n (\%) } \\
\hline RRMS $^{\mathrm{c}}$ & $173(82.0)$ & $46(87)$ & .22 & 317 (81.9) & $>.99$ \\
\hline PPMS $^{\text {d }}$ & $14(6.6)$ & $5(9)$ & & $25(6.5)$ & \\
\hline SPMS $^{\mathrm{e}}$ & $24(11.4)$ & $2(4)$ & & 45 (11.6) & \\
\hline \multicolumn{6}{|c|}{ Time since diagnosis, $\mathbf{n}(\%)$} \\
\hline$>1$ year & $47(22.3)$ & $9(17)$ & .04 & $119(30.7)$ & .06 \\
\hline$>5$ years & $79(37.4)$ & $11(21)$ & & $118(30.5)$ & \\
\hline$>10$ years & $85(40.3)$ & $33(62)$ & & $150(38.3)$ & \\
\hline \multicolumn{6}{|l|}{ DMT $^{\mathrm{f}}$ treatment, $\mathrm{n}(\%)$} \\
\hline No DMT & $45(21.3)$ & $16(30)$ & & $72(18.6)$ & \\
\hline Copaxone and interferons & $84(39.8)$ & $12(23)$ & & $140(36.2)$ & \\
\hline Oral $\mathrm{DMT}^{\mathrm{g}}$ & $57(27.0)$ & $17(32)$ & & $130(33.6)$ & \\
\hline Infused DMT ${ }^{\mathrm{h}}$ & $21(10.0)$ & $8(15)$ & & $41(10.6)$ & \\
\hline \multicolumn{6}{|c|}{ Duration of current treatment, $n(\%)$} \\
\hline $1-5$ years & $145(68.7)$ & $41(77)$ & & $295(76.2)$ & \\
\hline $6-10$ years & $40(19.0)$ & $7(13)$ & & $50(12.9)$ & \\
\hline $11-15$ years & $12(5.7)$ & $2(4)$ & & $24(6.2)$ & \\
\hline $16-20$ years & $10(4.7)$ & $1(2)$ & & $14(3.6)$ & \\
\hline$>20$ years & $4(1.9)$ & $2(4)$ & & $4(1.0)$ & \\
\hline \multicolumn{6}{|c|}{ Prior DMT treatment, $\mathbf{n}(\%)$} \\
\hline No DMT & $67(31.8)$ & $16(30)$ & .83 & $99(25.6)$ & .11 \\
\hline Copaxone and interferons & $148(70.1)$ & $43(60)$ & & $296(76.5)$ & \\
\hline Oral DMT & $21(10.0)$ & $11(21)$ & & $32(8.3)$ & \\
\hline
\end{tabular}




\begin{tabular}{llll}
\hline Characteristic & $\begin{array}{l}\text { Not linkable to PharMet- } \\
\text { rics Plus or Dx/Rx } \\
(\mathrm{N}=211)\end{array}$ & $\begin{array}{l}\text { Linkable to PharMet- } \\
\text { rics Plus } \\
(\mathrm{N}=53)\end{array}$ & $\begin{array}{l}P \text { value } \\
\text { Infused DMT }\end{array}$ \\
$22(10.4)$ & $5(9)$ & $\begin{array}{l}\text { Linkable to } \\
\text { Dx/Rx } \\
(\mathrm{N}=387)\end{array}$ \\
\hline 1 Relapse, $\mathrm{n}(\%)$ & $117(55.5)$ & $26(49)$ & $34(8.8)$ \\
\hline
\end{tabular}

${ }^{\mathrm{a}} \mathrm{Dx} / \mathrm{Rx}$ : merged medical claims (Dx) and prescription claims (Rx) database.

${ }^{\mathrm{b}} \mathrm{MS}$ : multiple sclerosis.

${ }^{\mathrm{c}}$ RRMS: relapsing-remitting multiple sclerosis.

${ }^{\mathrm{d}}$ PPMS: primary progressive multiple sclerosis.

eSPMS: secondary progressive multiple sclerosis.

fDMT: disease-modifying therapy.

${ }^{g}$ Oral DMTs include Gilenya, Tecfidera, and Aubagio.

${ }^{\mathrm{h}}$ Infused DMTs include Tysabri and Lemtrada.

Figure 4. Frequencies of the most common multiple sclerosis (MS) symptoms based on International Classification of Diseases codes on paid claims in the cohort linked to the PharMetrics Plus MS database (blue bars) and the overall PharMetrics Plus MS population (red bars). Only symptoms with prevalence $>10 \%$ are shown. Asterisk indicates $P<.05$.

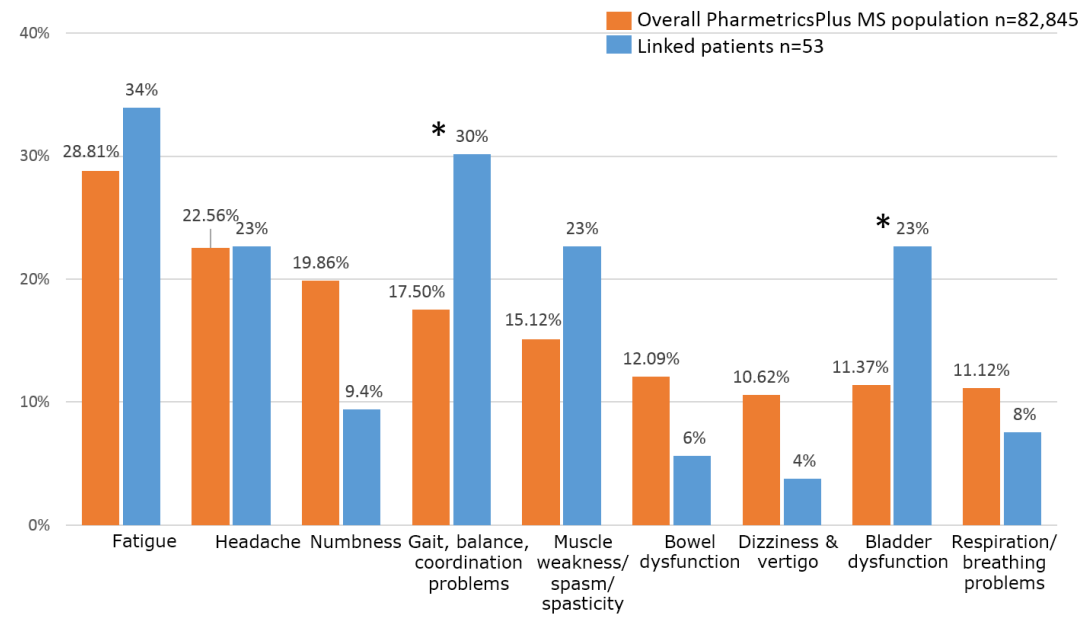

Figure 5. Use of multiple sclerosis (MS)-specific medication in the 1-year index period in the overall PharMetrics Plus MS cohort (red bars) and in the cohorts linked to the PharMetrics Plus MS (light blue bars) and Rx/Dx (dark blue bars) databases. DMT: disease-modifying therapy; Rx/Dx: merged prescription claims (Rx) and medical claims (Dx) database.

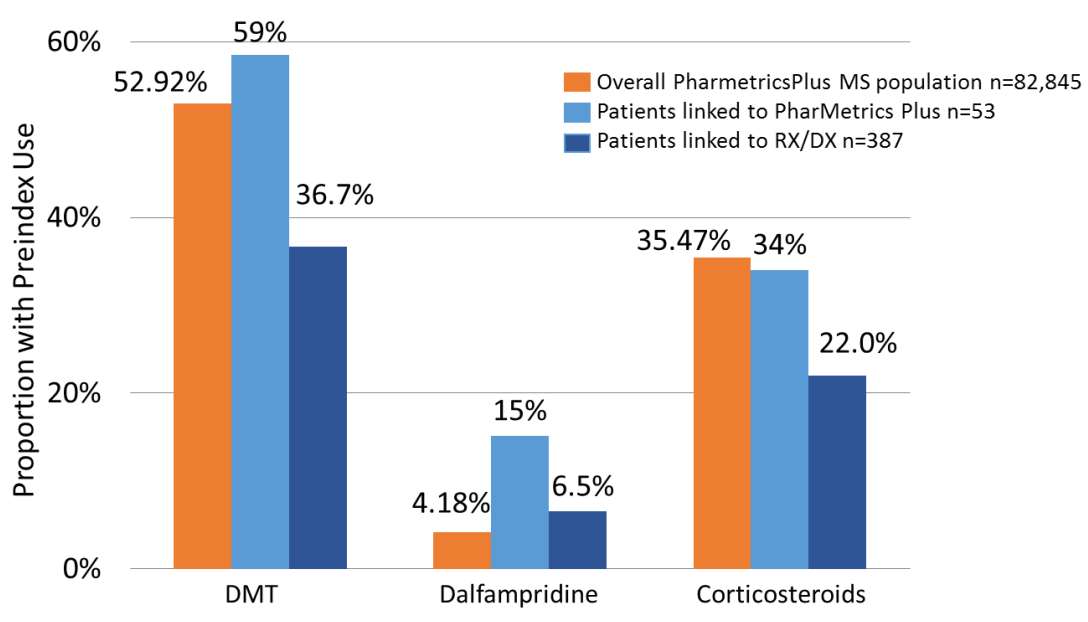




\section{Discussion}

\section{Principal Findings}

The aim of this study was to explore the feasibility of creating a dataset that contains both patient outcomes data (from a Web-based survey of US patients with MS recruited on an open Internet platform) and health care utilization information from pharmacy and medical claims databases. The initial results presented here indicate that this aim was fulfilled and that the survey population is broadly representative of the general MS patient population in the United States.

People with MS are highly active on social media $[18,19]$. We have previously shown that the demographics of cohorts of patients with MS identified by their activities on social media correspond well with cohorts identified in other sources, indicating that social media data analysis can be usefully applied to outcomes research [12]. Facebook, forums, and blogs have been used previously to recruit participants into surveys of health outcomes and lifestyle interventions in MS [20-22]. Our work differs in a number of important aspects from previous reports, however. First, patients were recruited through unbranded advertisements placed on Facebook pages, not by active, personal invitations sent to specific target groups. Although this approach led to a markedly lower rate of successfully completed surveys than that reported with patients invited directly, the absence of active targeting of participants can be expected to reduce the scope for bias and generate a more representative population.

The same differences apply to a very recent report that described successful linking of data from invited patients on a dedicated online patient community (PatientsLikeMe) with administrative claims data [13]. In contrast to our approach, targeted invitations were sent to eligible patients identified on the social network by email and private messages. Both approaches have their merits, but the population from the online patient community may well have been less diverse than patients who can be reached by untargeted advertisements on open Internet platforms such as Facebook.

The growing interest in linking health care-related social media content to information obtained by traditional means, for example, claims databases, reflects the realization that such linked data may provide a rapid, cost-effective, and credible method to capture patient outcomes, behavioral data, and health care claims. Our use of a standardized survey allowed us to overcome a common limitation of data from open Internet platforms: a lack of structured clinical, socioeconomic, and demographic data necessary for observational research [23]. The survey allowed us to obtain structured, disease-specific information on disease duration, medications, disabilities, and impact of the disease on quality of life as well as work productivity. The linkage to claims databases generated a dataset that combines patient-reported MS-related information and standardized data driven by the claims classification system. The linked database thus includes a wealth of information that is typically only available in separate databases. This could enable deeper and more rounded insights into burden of illness and other outcomes beyond what is possible with conventional database approaches. For example, complementing claims databases with patient-derived information on MS disease type would enable analyses of the impact of different types of MS on productivity or disability. Such information cannot be obtained from either data source in isolation. The potential to derive outcomes data was not assessed in this study but is currently being explored in future analysis of the database.

In our analysis, the concordance of the data, measured as PPV, between survey responses and both the claims databases used was high for diagnosis and current and prior DMT but lower for relapses. In the open-source database, relapse was based on a claims-based algorithm [24,25]. The survey was based on patient recall, which is typically less exact than data entered into claims databases.

The size of the cohort and the percentage of survey respondents linkable to the PharMetrics Plus database were relatively modest. There are several reasons for this, none of which invalidates the approach. The odds of successful linkage depend on the size and population coverage of the databases selected. Although it has a lower likelihood of missing claims, PharMetrics Plus is an order of magnitude smaller than the open-source databases and underrepresents patients from the western United States, which reduced the potential to link survey respondents from this region. These are weaknesses specific to the specific database, not to the method.

When expanding the linkage methodology to include databases such as electronic medical records [26], it is important to take the privacy aspect into account. It has been strongly argued that important privacy concerns must be interpreted alongside the social good that can come from this kind of health research [27-30]. In this study, the patient survey required active opt-in from the participants and no data were obtained from participants' Facebook accounts.

\section{Limitations}

There are weaknesses in the analysis. The sample size of 53 patients linked to the PharMetrics Plus database is too small to read much into the data, and the main value of this particular dataset is in demonstrating the feasibility of the method. The high linkage rates but low concordance with the Dx/Rx databases are noted, attributable to the open-source nature of the databases. As social media content is user driven, there is no independent verification of the correctness of the data, although the concordance analysis indicates that the social media information reflected patients' actual situations. This limitation applies to all social media analyses [31]. There is a wide range of trust in Web-based information [19], and differences in attitudes toward social media among patients with MS may produce a certain bias in the survey population toward those more willing to use and trust social media. All data are for US populations and the generalizability of the methods has yet to be established. There is a possibility of selection bias as participants were recruited by Web-based advertisements. From the survey results, the Facebook-recruited survey participants may have been somewhat more severely affected by their illness than the overall population. More symptomatic patients may be more motivated to complete a Web-based survey. Such bias toward more severely affected patients would also affect an 
analysis of MS-related costs. It should also be underlined that the survey relied on patient recall, which is less than $100 \%$ reliable [32]. The date for an event recorded by a patient in the survey may not correspond to the time point for the same event in the PharMetrics Plus database. However, given the large number of participants and the relatively high degree of linkage, these two risks do not seem to have invalidated the collected data.
With these limitations in mind, this study shows that the combination of advertisements on open Internet platforms and Web-based surveys may enable rapid gathering of real-life data on a large US population of representative patients with MS. The applicability of the approach to diseases other than MS would need independent verification.

\section{Acknowledgments}

This study was funded by Novartis Pharma AG, Basel, Switzerland. The study and questionnaire were designed collaboratively by Novartis and IMS Health. The authors thank Pelle Stolt, PhD, for editorial assistance.

\section{Authors' Contributions}

Data were collected and analyzed by IMS Health and interpreted by all authors. The manuscript was drafted by VR. All authors provided comments and additional interpretations at the writing stage. All authors approved the final manuscript.

\section{Conflicts of Interest}

VR, JM, and MO are employees of Novartis.

\section{Multimedia Appendix 1}

Survey questionnaire. The EQ-5D-3L and EQ-VAS instruments are proprietary and cannot be displayed in publicly available materials.

[PDF File (Adobe PDF File), 94KB-Multimedia Appendix 1]

\section{Multimedia Appendix 2}

Disclaimer presented to survey participants explaining confidentiality and handling of the data.

[PDF File (Adobe PDF File), 47KB-Multimedia Appendix 2]

\section{Multimedia Appendix 3}

Description of the databases used in the analysis.

[PDF File (Adobe PDF File), 29KB-Multimedia Appendix 3]

\section{References}

1. European Medicines Agency. 2013 Oct 18. The patient's voice in the evaluation of medicines Internet URL: http://www. ema.europa.eu/docs/en GB/document library/Report/2013/10/WC500153276.pdf [accessed 2016-08-31] [WebCite Cache ID 6kAs2dIbD]

2. US Food \& Drug Administration. United States Government Printing Offices. 2012. Food and Drug Administration Safety and Innovation Act (FDASIA) Internet URL: https://www.gpo.gov/fdsys/pkg/PLAW-112pub1144/pdf/PLAW-112publ144. pdf [accessed 2016-08-31] [WebCite Cache ID 6kAsJm4cq]

3. Stafinski T, Menon D, Nardelli A, Bakal J, Ezekowitz J, Tymchak W, et al. Incorporating patient preferences into clinical trial design: results of the opinions of patients on treatment implications of new studies (OPTIONS) project. Am Heart $\mathbf{J}$ 2015 Jan;169(1):122-31.e22. [doi: 10.1016/j.ahj.2014.10.002] [Medline: 25497257]

4. Salathé M, Khandelwal S. Assessing vaccination sentiments with online social media: implications for infectious disease dynamics and control. PLoS Comput Biol 2011 Oct;7(10):e1002199 [FREE Full text] [doi: 10.1371/journal.pcbi.1002199] [Medline: 22022249]

5. Vayena E, Salathé M, Madoff LC, Brownstein JS. Ethical challenges of big data in public health. PLoS Comput Biol 2015 Feb;11(2):e1003904 [FREE Full text] [doi: 10.1371/journal.pcbi.1003904] [Medline: 25664461]

6. Salathé M, Bengtsson L, Bodnar TJ, Brewer DD, Brownstein JS, Buckee C, et al. Digital epidemiology. PLoS Comput Biol 2012;8(7):e1002616 [FREE Full text] [doi: 10.1371/journal.pcbi.1002616] [Medline: 22844241]

7. Chunara R, Andrews JR, Brownstein JS. Social and news media enable estimation of epidemiological patterns early in the 2010 Haitian cholera outbreak. Am J Trop Med Hyg 2012 Jan;86(1):39-45 [FREE Full text] [doi: 10.4269/ajtmh.2012.11-0597] [Medline: 22232449] 
8. European Medicines Agency. 2014 Sep 08. Guideline on good pharmacovigilance practices (GVP): Module VI - Management and reporting of adverse reactions to medicinal products (Rev 1) Internet URL: http://www.ema.europa.eu/docs/en GB/ document library/Scientific guideline/2014/09/WC500172402.pdf [accessed 2016-08-31] [WebCite Cache ID 6kAsgj1Iq]

9. Sarker A, Ginn R, Nikfarjam A, O'Connor K, Smith K, Jayaraman S, et al. Utilizing social media data for pharmacovigilance: A review. J Biomed Inform 2015 Apr;54:202-212 [FREE Full text] [doi: 10.1016/j.jbi.2015.02.004] [Medline: 25720841]

10. Nakhasi A, Passarella R, Bell S, Paul M, Dredze M, Pronovost P. Malpractice and malcontent: Analyzing medical complaints in twitter. AAAI Tech Rep 2012 Apr;FS-12-05:84-85.

11. Selby P, van Mierlo T, Voci SC, Parent D, Cunningham JA. Online social and professional support for smokers trying to quit: an exploration of first time posts from 2562 members. J Med Internet Res 2010;12(3):e34 [FREE Full text] [doi: 10.2196/jmir.1340] [Medline: 20719739]

12. Risson V, Saini D, Bonzani I, Huisman A, Olson M. Patterns of Treatment Switching in Multiple Sclerosis Therapies in US Patients Active on Social Media: Application of Social Media Content Analysis to Health Outcomes Research. J Med Internet Res 2016;18(3):e62 [FREE Full text] [doi: 10.2196/jmir.5409] [Medline: 26987964]

13. Eichler GS, Cochin E, Han J, Hu S, Vaughan TE, Wicks P, et al. Exploring Concordance of Patient-Reported Information on PatientsLikeMe and Medical Claims Data at the Patient Level. J Med Internet Res 2016;18(5):e110 [FREE Full text] [doi: 10.2196/jmir.5130] [Medline: 27174602]

14. Epstein M, International Society of Pharmacoepidemiology. Guidelines for good pharmacoepidemiology practices (GPP). Pharmacoepidemiol Drug Saf 2005 Aug;14(8):589-595. [doi: 10.1002/pds.1082] [Medline: 15918159]

15. von Elm E, Altman DG, Egger M, Pocock SJ, Gøtzsche PC, Vandenbroucke JP. The Strengthening the Reporting of Observational Studies in Epidemiology (STROBE) Statement: guidelines for reporting observational studies. Int J Surg 2014 Dec;12(12):1495-1499 [FREE Full text] [doi: 10.1016/j.ijsu.2014.07.013] [Medline: 25046131]

16. World Medical Association. 2008. WMA Declaration of Helsinki - Ethical Principles for Medical Research Involving Human Subjects, amended by the 59th WMA General Assembly, Seoul, October 2008 Internet URL: http://http//:www. wma.net/en/30publications/10policies/b3/index.html.pdf [accessed 2016-08-31] [WebCite Cache ID 6kAtEm5Rs]

17. IMS Health. 2016. HEOR Bibliographies URL: http://www.imsheorbibliography.com/ [accessed 2016-08-05] [WebCite Cache ID 6jWvOKQ6k]

18. Shirazipour CH, Baillie CP, Galaviz K, Jarvis JW, Latimer-Cheung AE. Evaluating the theoretical content of online physical activity information for people with multiple sclerosis. Int J MS Care 2015;17(2):91-100 [FREE Full text] [doi: 10.7224/1537-2073.2013-048] [Medline: 25892979]

19. Colombo C, Mosconi P, Confalonieri P, Baroni I, Traversa S, Hill SJ, et al. Web search behavior and information needs of people with multiple sclerosis: focus group study and analysis of online postings. Interact J Med Res 2014;3(3):e12 [FREE Full text] [doi: 10.2196/ijmr.3034] [Medline: 25093374]

20. Hadgkiss E, Jelinek G, Weiland T, Pereira N, Marck C, van der Meer D. Methodology of an International Study of People with Multiple Sclerosis Recruited through Web 2.0 Platforms: Demographics, Lifestyle, and Disease Characteristics. Neurol Res Int 2013;2013:1-12 Article ID 580596 [FREE Full text] [doi: 10.1155/2013/580596] [Medline: 23691313]

21. Jelinek GA, Weiland TJ, Hadgkiss EJ, Marck CH, Pereira N, van der Meer D. Medication use in a large international sample of people with multiple sclerosis: associations with quality of life, relapse rate and disability. Neurol Res 2015 Aug;37(8):662-673 [FREE Full text] [doi: 10.1179/1743132815Y.0000000036] [Medline: 25905471]

22. Weiland T, Jelinek G, Marck C, Hadgkiss E, van der Meer D, Pereira N, et al. Clinically significant fatigue: prevalence and associated factors in an international sample of adults with multiple sclerosis recruited via the internet. PLoS One 2015;10(2):e0115541 [FREE Full text] [doi: 10.1371/journal.pone.0115541] [Medline: 25692993]

23. Chary M, Genes N, McKenzie A, Manini AF. Leveraging social networks for toxicovigilance. J Med Toxicol 2013 Jun;9(2):184-191 [FREE Full text] [doi: 10.1007/s13181-013-0299-6] [Medline: 23619711]

24. Chastek BJ, Oleen-Burkey M, Lopez-Bresnahan MV. Medical chart validation of an algorithm for identifying multiple sclerosis relapse in healthcare claims. J Med Econ 2010;13(4):618-625. [doi: 10.3111/13696998.2010.523670] [Medline: 20883151]

25. Ollendorf DA, Jilinskaia E, Oleen-Burkey M. Clinical and economic impact of glatiramer acetate versus beta interferon therapy among patients with multiple sclerosis in a managed care population. J Manag Care Pharm 2002;8(6):469-476 [FREE Full text] [doi: 10.18553/jmcp.2002.8.6.469] [Medline: 14740608]

26. Cascade E, Marr P, Winslow M, Burgess A, Nixon M. Conducting research on the Internet: medical record data integration with patient-reported outcomes. J Med Internet Res 2012;14(5):e137 [FREE Full text] [doi: 10.2196/jmir.2202] [Medline: 23060427]

27. Verma IM. Editorial expression of concern: Experimental evidence of massive-scale emotional contagion through social networks. Proc Natl Acad Sci U S A 2014 Jul 22;111(29):10779 [FREE Full text] [doi: 10.1073/pnas.1412469111] [Medline: 24994898]

28. Goel V. NY Times Internet. 2014 Aug 12. As Data Overflows Online, Researchers Grapple With Ethics URL: http://www. nytimes.com/2014/08/13/technology/the-boon-of-online-data-puts-social-science-in-a-quandary.html? r=2 [accessed 2016-08-22] [WebCite Cache ID 6SVvgOJ3k] 
29. Padrez KA, Ungar L, Schwartz HA, Smith RJ, Hill S, Antanavicius T, et al. Linking social media and medical record data: a study of adults presenting to an academic, urban emergency department. BMJ Qual Saf 2015 Oct 13:1-10. [doi: 10.1136/bmjqs-2015-004489] [Medline: 26464519]

30. Kahn JP, Vayena E, Mastroianni AC. Opinion: Learning as we go: lessons from the publication of Facebook's social-computing research. Proc Natl Acad Sci U S A 2014 Sep 23;111(38):13677-13679 [FREE Full text] [doi: 10.1073/pnas.1416405111] [Medline: 25217568]

31. Goff DA, Kullar R, Newland JG. Review of Twitter for infectious diseases clinicians: useful or a waste of time? Clin Infect Dis 2015 May 15;60(10):1533-1540. [doi: 10.1093/cid/civ071] [Medline: 25652087]

32. Prince SA, Adamo KB, Hamel ME, Hardt J, Connor GS, Tremblay M. A comparison of direct versus self-report measures for assessing physical activity in adults: a systematic review. Int J Behav Nutr Phys Act 2008;5:56 [FREE Full text] [doi: $\underline{10.1186 / 1479-5868-5-56]}$ [Medline: $\underline{18990237]}$
Abbreviations
DMT: disease-modifying therapy
HIPAA: Health Insurance Portability and Accountability Act
https: hypertext transfer protocol, secure
MS: multiple sclerosis
PPV: positive predictive value
STROBE: Strengthening the Reporting of Observational Studies in Epidemiology

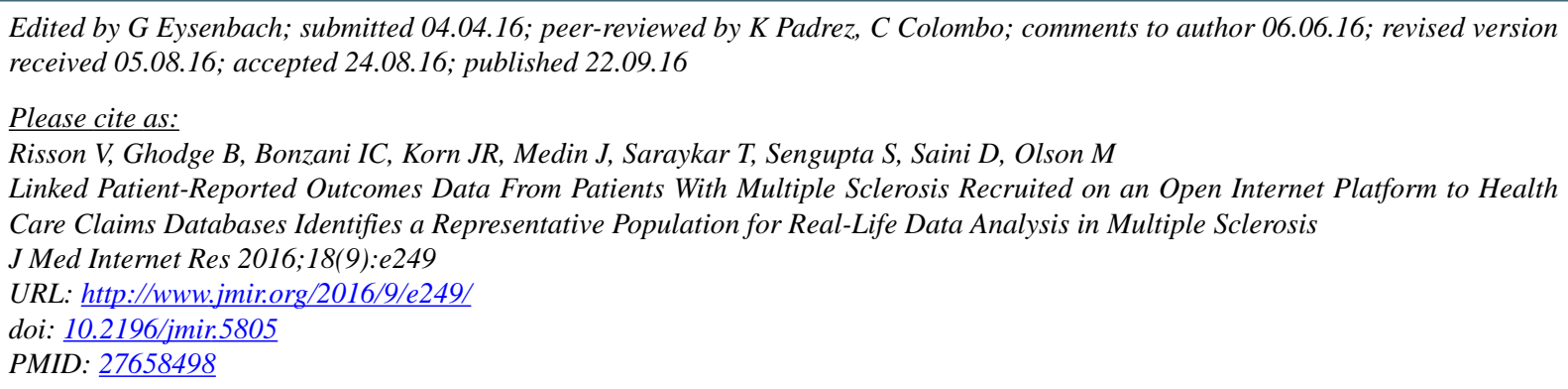

(C) Valery Risson, Bhaskar Ghodge, Ian C Bonzani, Jonathan R Korn, Jennie Medin, Tanmay Saraykar, Souvik Sengupta, Deepanshu Saini, Melvin Olson. Originally published in the Journal of Medical Internet Research (http://www.jmir.org), 22.09.2016. This is an open-access article distributed under the terms of the Creative Commons Attribution License (http://creativecommons.org/licenses/by/2.0/), which permits unrestricted use, distribution, and reproduction in any medium, provided the original work, first published in the Journal of Medical Internet Research, is properly cited. The complete bibliographic information, a link to the original publication on http://www.jmir.org/, as well as this copyright and license information must be included. 